\title{
A INVISIBILIDADE NEGRA NA CIDADE DE PORTO ALEGRE: UMA PESQUISA SOBRE IMAGINÁRIOS URBANOS
}

\author{
The black invisibility in the city of Porto Alegre: an urban imaginaries \\ research
}

HelenaBonetto*

*Professora Doutora do Estado do Rio Grande do Sul - geohelenabonetto@gmail.com

\author{
Recebido em 30/06/2019. Aceito para publicação em 30/07/2019. \\ Versão online publicada em 10/09/2019 (http://seer.ufrgs.br/paraonde)
}

\begin{abstract}
Resumo:
O artigo versa sobre os imaginários urbanos de Porto Alegre, a invisibilidade dos negros como sujeitos históricos que construíram esta cidade, mas que, no entanto, não se encontram representados nos imaginários urbanos da cidade, fortemente marcados pela imigração europeia e exaltados a partir dela.
\end{abstract}

Palavras-chave: imaginário; invisibilidade; cidade

\begin{abstract}
:
The article deals with the urban imaginaries of Porto Alegre, the invisibility of the blacks as historical subjects who built this city, but who are not represented on its urban imaginaries, strongly marked by European immigration and exalted from it.
\end{abstract}

Key-words: Imaginary; invisibility; City.

\section{Introdução}

O presente trabalho fez parte de um projeto maior de investigação de doutoramento em andamento no Programa de Pós-Graduação em Geografia da Universidade Federal do Rio Grande do Sul, intitulado - A invisibilidade negra na cidade de Porto Alegre: uma pesquisa sobre imaginários urbanos, a qual se encontra no seu quarto ano de desenvolvimento. O objetivo deste artigo é evidenciar a invisibilidade negra no Estado do Rio Grande do Sul e em Porto Alegre, aprofundar as reflexões teóricas dos estudos sobre imaginários urbanos, estabelecendo um diálogo com resultados preliminares do corpus da pesquisa. A primeira etapa foi revisão bibliográfica da história de Porto Alegre, campo exploratório nos projetos do Museu do Percurso Negro e os Territórios Negros. A revisão bibliográfica sobre imaginários urbanos foi realizada a partir da abordagem teórica de autores: Alicia Lindón e Daniel Hiernaux, os quais se destacam pela valorização do simbólico na compreensão dos fenômenos urbanos. Para os autores, os imaginários urbanos possibilitam ao pesquisador o entendimento das diferentes formas de habitar o espaço urbano e desvelam lugares que estão invisíveis nas grandes cidades. Sobre os imaginários urbanos, se faz necessário destacar que para Lindón (2007a, 2007b) são processos de qualificação dos lugares da cidade através das práticas socioespaciais dos sujeitos em determinados lugares da cidade, não estão desvinculados da história, da realidade dos lugares e ainda são compartilhados socialmente. Diante disso, foram traçadas estratégias metodológicas para compreender os imaginários urbanos relativos à cidade de Porto Alegre e a invisibilidade dos negros 
como sujeitos e agentes transformadores do espaço. As estratégias incluíram a conversa com pessoas que circulam no centro da cidade de Porto Alegre pelos marcos do Museu do Percurso Negro, escuta de narrativas de sujeitos envolvidos diretamente com a temática da pesquisa e por fim, análise do jornal Correio do Povo nos seguintes eventos: Aniversário de Porto Alegre, Comemorações da Revolução Farroupilha e Dia da Consciência Negra. Os principais conceitos abordados são: imaginários urbanos, raça e invisibilidade.

O trabalho pretende demonstrar a permanente invisilidade das contribuições dos negros para a formação da cidade de Porto Alegre e do Estado do Rio Grande do Sul a partir da análise preliminar dos dados coletados para tese e como esse fato contribui para alimentar ainda o imaginário dominante de que Porto Alegre é uma cidade branca marcada e exaltada através da memória e do legado dos imigrantes europeus que estiveram presentes ao longo de sua história, apesar da série de iniciativas para tornar visível a importância histórica dos negros como sujeitos e agentes do espaço urbano.

O artigo está dividido em: Invisibilidade Negra no Rio Grande do Sul e em Porto Alegre, Os Imaginários Urbanos e resultados preliminares da análise dos dados levantados para a construção do corpus da pesquisa.

\section{Desenvolvimento}

Na produção científica sobre o Negro no Rio Grande do Sul (RS) encontramos com frequência 0 argumento da invisibilidade dos negros como sujeitos históricos em diferentes dimensões, tais como: econômica, cultural, religiosa, artística, histórica, territorial, entre outras para além do período escravocrata. Entre os trabalhos que reivindicam a presença negra como sujeitos históricos no RS, estão: Leite (1996), Bakos e Bernard (1991) Oliven (1996), Santos (2005), Bittencourt Jr (1995; 2005;), Santos (2005), Rosa (2014) entre outros.

A explicação para Leite (1996) da invisibilidade dos negros no perfil étnico da população gaúcha se deve à forte valorização dos elementos ligados à imigração de italianos e alemães para esta região do país. Segundo Santos (2005) a presença branca no Rio Grande do Sul está fartamente documentada, enquanto a negra aparece nos documentos de forma subalterna e ocasional (SANTOS, 2005, p.25). Para Leite (1996) a invisibilidade dos negros na Região Sul se deve pelas políticas de branqueamento que trouxeram imigrantes de países europeus para o sul do país, a negligência pelas políticas públicas, pelas pesquisas acadêmicas, pelas formas de representação literária e pela segregação socioespacial. A autora é enfática ao escrever que os negros foram tratados como inexistentes nesta região do Brasil.

Em Leite (1996) encontramos que a invisibilidade dos negros no sul do país, é o resultado de uma política de branqueamento que atingiu seu sucesso nessa região. A política de branqueamento, adotada pelo Estado Brasileiro entre o século XIX e início do século $X X$ se concretizaram, sendo elas responsáveis pela invisibilização dos negros nos estados do sul. Os "ex-escravos" eram considerados como um entrave para o desenvolvimento do país e de uma "verdadeira nação".

A defesa do branqueamento via sul do Brasil se justificava por um vazio estatístico que deveria ser ocupado pelos imigrantes europeus; para Leite (1996) a invisilidade dos negros é um dos suportes da ideologia do branqueamento, podendo ser identificada em 
diferentes tipos de práticas representações. Em Leite (1996) encontramos que a noção de invisibilidade foi utilizada pela primeira vez por Ralph Ellison em 1990 para falar da invisibilidade dos negros na sociedade norte-americana- este era o tema do romance Homem Invisível.

Leite (1996) afirma que ao contrário da identidade brasileira inclusiva, a identidade do sul é construída a partir da negação do negro, sendo a principal constituinte dessa identidade no âmbito da Nação, a branquidade dos imigrantes europeus e assim desde o século XIX, branqueando as práticas e as representações do sul e efetivando o sucesso da política migratória e de uma ideologia racista (LEITE, 1996, p.50).

Para Oliven (1996) "a chave da invisibilidade não estaria apenas na questão de autoclassificação de cor e mais na invisibilidade social e simbólica do negro no RS (OLIVEN, 1996, p.25)". Ruben Oliven (1996) afirma que a historiografia tradicional invisibilizou a presença negra no estado do RS, afirmando que ao contrário do que aconteceu em outros estados brasileiros, como a Bahia, no qual o negro encontra-se entre o perfil étnico da população, no Rio Grande do Sul existe o reconhecimento do negro quanto escravizado, mas não como formador da identidade gaúcha.

Ainda em Oliven (1996) a identidade do gaúcho estaria nas peculiaridades que envolvem a formação do Rio Grande do Sul, como por exemplo: a posição estratégica de fronteira, o seu povoamento e a integração tardia ao Brasil contribuíram para a construção da identidade gaúcha calcada em passado rural que tem como cenário o pampa e na figura idealizada do gaúcho.

No artigo sobre o imaginário étnico da população do Rio Grande do Sul, Mário Maestri (2008), vai além aos questionamentos sobre as representações do perfil étnico da formação do RS, partindo da pintura feita por Aldo Locatelli (1915-1962) na sala de reuniões do Palácio Piratini, sede do poder executivo do estado do Rio Grande do Sul para estruturar seu argumento sobre a invisilidade dos negros nas representações sobre a população do RS. No painel estão representados: os lusitanos, os nativos guaranis, os bandeirantes paulistas e lagunenses e os colonos italianos e alemães. Para Maestri, Aldo Locatelli só reproduziu o que estava presente no imaginário da população riograndense da época, não existindo lugar para o negro escravizado e tão pouco como trabalhador, conforme:

É como se seu sangue e suor jamais tivessem frutificado o solo rio-grandense. Uma visão assumida, alimentada e ampliada pela historiografia, que negou-minimizou a importância da escravidão e do cativo na construção do Rio Grande. Hoje há consenso sobre a importância da escravidão na antiga formação social rio-grandense, que alguns autores definem como dominantemente escravista (MAESTRI, 2008, p.54).

Maestri (1994) é categórico nesta divisão do trabalho, dizendo que o grupo que veio para colonizar é: branco e não raro portugueses natos e em contraponto aos negros que foram traficados para este estado para trabalhar nas charqueadas, nas lavouras, transportes aquáticos, olarias entre outros. Entretanto, mesmo sabendo desta realidade criou-se um mito de que a presença negra neste estado é quase que insignificante e que não teria sido fundamental para o desenvolvimento do RS. A historiografia contribuiria para alimentar o imaginário étnico do Rio Grande do Sul de que apenas os imigrantes brancos europeus contribuíram para desenvolvimento desse estado. 
A capital do estado RS, não está imune aos contextos descritos acima; ao longo da história da cidade, certos grupos sociais são lembrados por seus papéis desempenhados, como por exemplo: no mito fundador de Porto Alegre para Pesavento (1999) está relacionado com imigração dos casais açorianos:

Porto Alegre teria nascido sobre uma aldeia indígena, foi dividida em três sesmarias, recebeu os casais açorianos no século XVIII e uma imigração europeia nos séculos XIX e XX. Entretanto, celebra seu aniversário rememorando apenas o passado da colonização açoriana, pagando a ancestral - e teimosamente atual - "presença indígena, assim como os dos outros imigrantes e a dos negros escravizados que também não são lembrados nos meios de comunicação. (PESAVENTO, 1999, p. 88)".

Os imigrantes alemães também possuem referências da sua presença em Porto Alegre, ganhando até um período na história da cidade que abrange a segunda metade do século XIX até 1930. Singer (1977) chamou de "a cidade dos alemães", a referência aos alemães segundo Monteiro (1995) teria vindo:

Nesse período, crescia a influência da presença alemã na cidade com as práticas de esportes como o ciclismo, o remo e o tiro. Valorizavam-se o rio e os arraiais para passeios e piqueniques. Fundam-se uma série de sociedades e clubes congregando a comunidade imigrante. A influência também estava presente no estilo arquitetônico dos prédios, nos estabelecimentos comerciais, nas novas empresas e nas sociedades fundadas" (MONTEIRO, 1995, p. 33).

Para Pesavento (1995) Os imigrantes Alemães no final do século XIX constituem uma grande parte da elite de Porto Alegre. Assim como no restante do estado, o branqueamento da cidade acontecia na medida em que se intensificava a imigração europeia para o sul do país.

Os locais de concentração negra em Porto Alegre foram historicamente sendo apagados da cidade em diferentes escalas. Bairros foram removidos, ruas as quais se identificavam com a presença negra em Porto Alegre tiveram seus nomes trocados, como por exemplo: A Colônia Africana segundo Kersting:

A área da Colônia Africana corresponde a uma parte do atual bairro Rio Branco, onde se encontra as ruas Castro Alves, Casemiro de Abreu, Vasco da Gama, Liberdade e Cabral, correndo em direção oeste-leste, e as ruas Mariante e Esperança (atual Miguel Tostes) aproximadamente correndo na direção norte-sul. (KERSTING, 1998, p. 101).

A Colônia Africana foi objeto de estudo de Pesavento (1995), Kersting (1998), Rosa (2014). Não podemos analisar de forma ingênua seu esquecimento na história de Porto Alegre; naquele local residiam aqueles que deveriam ser banidos, aqueles deveriam ser varridos da cidade, pois não representavam a modernidade, a civilidade, aquilo que as elites e a gestão da Porto Alegre da época desejava para a cidade. Em Pesavento (1995) encontramos uma importante reflexão sobre a Porto Alegre do século XIX e a exclusão dos negros da cidade- a pesquisadora vai abordar os caminhos da construção dos imaginários sociais de Porto Alegre a partir das crônicas antigas e da imprensa local.

Pesavento (1995) nos esclarece o papel importante da impressa nesta construção. Os jornais da época foram determinantes na construção do imaginário social da Colônia 
Africana, pois estavam sempre vinculando notícias que depreciavam o local, tais como: crimes, marginalidade, bagunça, desordem e estavam sempre associando os moradores negros com a marginalidade. Além da Colônia Africana, Pesavento (1995) nos fala sobre outros locais da cidade. Para a autora a centralidade de Porto Alegre e a sua modernização fez com que os negros fossem expulsos da cidade. Compreende que para os gestores da época o centro da cidade deveria ser o cartão postal e deveria se promover uma verdadeira varredura dos pobres daquele local. A pesquisadora afirma que poderíamos encontrar negros por todas as ruas, conforme:

em tempos de escravidão, os negros partilhavam os espaços dos brancos moradores da urbe, porque constituíam o que se poderia chamar de parte de seu patrimônio e do pessoal de casa. Mas, nos referimos aos territórios negros da cidade e seu processo de exclusão do espaço urbana que se construía (PESAVENTO, 1995, p. 82).

Entre os territórios negros estava a cidade baixa. O nome desta região da cidade não se dá apenas pela topografia do local, mas das características da população que lá habitava. Na cidade baixa encontramos segundo Pesavento (1995) gente de menor importância, que não tinha maiores posses para morar na cidade alta, a área é reconhecida como território negro também por ser um refúgio para os escravos fugidos da servidão (PESAVENTO, 1995, p.82).

A pesquisadora faz referência ao imaginário social da época que envolvia uma parte da cidade baixa que se limitava entre as ruas Venâncio Aires e República, João Pessoa, chamado de emboscada, conhecida como um local violento e de crime. Para Pesavento as emboscadas representavam para os negros fugidos a anti-imagem da liberdade, primeiro pouso de uma fuga, sendo que para os ocupantes da franja urbana de Porto Alegre a violência significa as ações dos capitães do mato para capturar os negros fujões dos seus senhores (PESAVENTO, 1995).

Para Pesavento (1995) há sempre um contraponto entre ordem e desordem em Porto Alegre, a desordem estaria ligada aos locais em que a população negra residia e a ordem e a civilidade que estabelecia com a burguesia e com a cidade Branca. E ainda, com crescimento, a desescravização e a modernização da cidade aumentaram as dificuldades para a população negra obter moradia no Centro. Conforme Pesavento, formou-se um cinturão negro em torno da cidade (lembrando que o atual Centro Histórico compreende a cidade de Porto Alegre do século XIX) branca que se aburguesava lentamente, embelezando-se conforme os processos do século.

Não podemos esquecer que a modernização da cidade seguia os princípios da higienização, estéticos e morais, empurrando para arrabaldes das cidades todos aqueles que eram indesejáveis, não podiam ser vistos e não correspondiam ao ideal de cidade que Porto Alegre gostaria de se tornar, é claro que no projeto de modernização da cidade todos aqueles que não se enquadravam nesse ideal estavam automaticamente excluídos de Porto Alegre.

Germano (2008) afirma que a expulsão dos negros para periferia de Porto Alegre é antiga, vem desde a "limpeza" dos becos no século XIX, da modernização que de acordo com a pesquisadora removeu: 
de 1950, como a llhota. A remoção desses núcleos levou à constituição de bairros periféricos como a Restinga, Vila Jardim e outros, que têm sua origem na desterritorialização de áreas negras da cidade, como Cabo Rocha, Ilhota, Colônia Africana e Areal da Baronesa (GERMANO, 2008, p. 104).

Outros locais também foram renomeados, esquecidos e não são lembrados ou associados à presença negra em Porto Alegre, como por exemplo: a rua principal do bairro Santana até o século XIX, segundo a pesquisa sobre a história dos bairros, era chamada de Rua dos Pretos Forros, em 1887, passa a ser 28 de setembro fazendo uma homenagem à promulgação da Lei do Ventre Livre e em 1885 passa a ser denominada Santana.

Diante do contexto assinalado acima, a tese deste trabalho busca evidenciar que os imaginários urbanos relativos a Porto Alegre no período da década de 1990-2015, existem jogos de invisibilidade/visibilidade da presença/memória/ legado negro na cidade, sendo que quando são visíveis estão relacionados com os lugares topofóbicos. Apesar da série de iniciativas para tornar visível a sua importância dos negros como sujeitos históricos, ainda perdura o imaginário de que Porto Alegre é cidade branca marcada e exaltada através da memória e do legado dos imigrantes europeus que estiveram presentes ao longo de sua história desta cidade.

Partimos também das definições e abordagens teóricas dos imaginários urbanos. Até os anos noventa, os estudos urbanos tradicionais centravam-se em aspectos materiais da cidade, tais como: a economia, a população, a política, entre outros. Contudo, nos últimos anos, este campo de estudo tem se aberto para abordagens que resgatam a dimensão simbólica da cidade. Entre estas abordagens, encontramos os estudos sobre os imaginários urbanos dos autores Alicia Lindón e Daniel Hiernaux. Para Hiernaux (2007b, 2008x), o estudo dos imaginários urbanos oferece a possibilidade de renovação do campo dos estudos urbanos. No entanto, Lindón (imaginários) destaca que, apesar da produção numerosa de estudos sobre o imaginário urbano, não se tem entrado num consenso sobre sua denominação.

É dentro deste contexto que Hiernaux (2008) define como imaginários urbanos "a aquellos imaginarios sociales construidos social y esencialmente a partir de las imágenes y representaciones de la ciudad." (HIERNAUX, 2008, p. 18). Para Lindón (2007) os imaginários são construções sociais, coletivas, as quais são compartilhadas socialmente, influenciando e orientando as práticas e discursos dos sujeitos sociais.

Para Hiernaux $(2007,2008)$ os imaginários urbanos são formados através de processos dinâmicos, os quais conferem significados às representações da cidade. Para Hiernaux (2007), é nesses processos que se encontra a força criativa dos imaginários, pois eles vão além das simples representações, criando imagens que guiam e orientam as ações dos sujeitos sociais.

Nesse sentindo, Hiernaux (2007a) destaca que, através dos estudos sobre o imaginário do espaço urbano, é possível reconstruir lugares da cidade como um todo ou apenas fragmentos dela. Para Lindón (2007a), a cidade é como um mosaico de lugares que foram socialmente construídos em um processo inacabado. O espaço urbano, com seus lugares, condensa valores, normas, símbolos e imaginários sociais. Entre esses imaginários sociais encontramos os imaginários urbanos, os quais estão relacionados diretamente com o habitar na cidade. Para Lindón (2007), os imaginários urbanos se constituem como uma trama de significados que qualificam os lugares da cidade de 
diferentes formas.

Segundo Lindón (2007), o processo de qualificação dos lugares pelos imaginários urbanos é complexo, pois esses imaginários são compartilhados socialmente, dão sentido a certos lugares e os conferem características de forma particular. Portanto, para Lindón (2007), os imaginários urbanos são definidos como uma trama de significados, dos quais os sujeitos se valem para construírem e reconstruírem os lugares das cidades.

Hiernaux (2007) ressalta que as diferentes formas de habitar a cidade acabam por expressar diferentes imaginários urbanos, ou seja, sujeitos sociais de diferentes grupos constroem diferentes imaginários. Assim, existem imaginários urbanos masculinos, femininos, noturnos, diurnos, entre outros. Em Hiernaux (2007a) encontramos o papel dos meios de comunicação de massa na construção dos imaginários urbanos atuais, pelo bombardeio de imagens que oferecem ao público que as consomem.

Em seus estudos o autor ainda evidencia que os imaginários urbanos estão ligados ao prazer ou gosto que os sujeitos sociais têm com determinados lugares, os quais são denominados como topofílicos. Por outro lado, encontramos imaginários que estão relacionados ao rechaço a certos lugares, os quais são chamados de topofóbicos.

\section{Considerações Finais}

A trajetória desta pesquisa constitui-se primeiramente pela construção de um corpus que engloba diferentes formas de narrar a cidade. Entre elas estão: as narrativas dos meios de comunicação de grande circulação, as quais correspondem às mídias locais escritas ou faladas, as narrativas históricas ditas oficiais, trabalhos representativos identificados como expressão da histórica local, as narrativas literárias, textos escritos de diferentes gêneros: crônicas, poemas, romances entre outros, as narrativas imagéticas compostas por fotografias das cidades e de seus moradores, as narrativas culturais: músicas, obras presentes na cidade, grafite, peças de teatro representadas nas ruas e nos teatros sobre a cidade, as narrativas do desenho urbano: nome de ruas, praças, monumentos, arquitetura. Entre outros aspectos, as narrativas dos sujeitos moradores da cidade, sempre identificados com uma coletividade organizados para levantar bandeira que acreditam importantes para a cidade em que residem ou simplesmente agregados por elementos que os identificam e os aproximam, os quais permitam compartilhar espaços de trocas de experiências, de lembranças ou memórias e as narrativas turísticas- como a cidade é vendida para os turistas, quais os atrativos são ressaltados para que ela se torne um lugar atrativo a ser visitado.

As ferramentas utilizadas para coleta dos dados foram entrevistas com pessoas que transitam pelo Museu do Percurso Negro de Porto Alegre; são escolhidas de forma aleatória e até o momento foram realizadas 40 entrevistas, seguindo o roteiro curto, um questionário online, levantamento de nome de ruas, material turístico, material fotográfico e entrevistas narrativas com sujeitos negros envolvidos diretamente com os projetos estudados, com produções intelectuais e militantes.

Os resultados preliminares permitiram o levantamento de símbolos que compõem os imaginários urbanos de Porto Alegre, símbolos que na maioria das vezes nos remetem aos imigrantes europeus de diferentes grupos culturais, tais como: italianos, alemães, judeus, entre outros. A simbologia relacionada aos grupos culturais negros ainda não é lembrada ou é totalmente invisibilizada. Os dados preliminares levam a crer que a tese 
de que os imaginários urbanos da cidade de Porto Alegre ainda permanecem marcados como símbolos pelos grupos culturais de herança dos imigrantes europeus e estão historicamente representados no espaço da cidade através de nomes de ruas, de monumentos, como patronos da feira do livro, entre outros símbolos.

Entendo que os imaginários urbanos a partir de Lindón (2012) como processos que qualificam os lugares e os símbolos que marcam a cidade de Porto Alegre apresentam diretamente grupos de imigrantes que estão representados em nomes de ruas, em passeios turísticos, em monumentos, bem como escritores e outros símbolos que marcam a cidade, compreendemos que mesmo com inciativas como o Museu do Percurso Negro, a Exposição Porto Negro, as obras de Irene dos Santos - (2005) e os Territórios Negros, a cidade continua alimentando um imaginário dominante relacionado com a imigração europeia e invisibilizando as mãos negras que foram e são sujeitos históricos que construíram Porto Alegre.

\section{Referências}

BITTENCOURT JR, Yosvaldir. A Esquina do Zaire: Territorialidade negra urbana em Porto Alegre. In: LEITE, Ilka Boaventura (Org.). Negros no sul do Brasil: invisibilidade e territorialidade. Florianópolis: Letras Contemporâneas, 1996. p. 215-225.

BOAVENTURA. Leite Ilka (Org.). Negros no sul do Brasil: invisibilidade e territorialidade. Florianópolis, Letras Contemporâneas, 1996. 284 p.

BONETTO, Helena. Invisibilidade negra na cidade de Porto Alegre : uma pesquisa sobre imaginários urbanos. 2018. 238 f. Tese (Doutorado) - Curso de Geografia, Universidade Federal do Rio Grande do Sul, Porto Alegre, 2018.

BONETTO, Helena. As Percepções topofílicas/topofóbicas das lideranças comunitárias do bairro Restinga antes e depois da implementação do orçamento participativo. 2013. 131f. Dissertação em Geografia -Universidade Federal do Rio Grande do sul.

GERMANO, Íris. Carnavais de Porto Alegre: etnicidade e territorialidades negras no sul do país. In: SILVA, Gilberto Ferreira da; SANTOS, José Antônio dos; CARNEIRO, Luiz Carlos da Cunha. RS NEGRO: cartografia sobre a produção de conhecimento. Porto Alegre: Edipucrs, 2008. p. 100-122.

HIERNAUX, Daniel. Los Imaginarios Urbanos: De la teoría y los aterrizajes en los estudios urbanos. Revista Latinoamericana de Estudios Urbano-Regionales. Instituto de Estudios Urbanos y Territoriales, Pontificia Universidad Católica de Chile - EURE. v. 33, n. 99, ago. 2007. p.17-30. Disponível em: <http://www.scielo.cl/pdf/eure/v33n99/art04.pdf>. Acesso em: 12 jul. 2012.

HIERNAUX, Daniel; LINDÓN, Alicia. Imaginarios urbanos desde América Latina. Tradiciones y nuevas perspectivas. Imaginarios urbanos en América Latina: urbanismos ciudadanos, Fundación Antoni Tapies, Barcelona, 2007, p.157-167.

KERSTING, Eduardo Henrique de Oliveira. Negros e a modernidade urbana em Porto Alegre: a Colônia Africana (1890-1920). Dissertação de Mestrado. PPGH/UFRGS. Porto Alegre, 1998. LINDÓN, Alicia. La ciudad y la vida urbana a través de los imaginarios urbanos. Revista Eure, Santiago de Chile, v. 33 , n. 99, p.7-16, ago. 2007c. Disponível em: <http://www.scielo.cl/pdf/eure/v33n99/art02.pdf>. Acesso em: 03 maio 2012.

MAESTRI, Mário. O negro e o imaginário étnico gaúcho. In: Diversidade étnica e 
identidade gaúcha. Santa Cruz do Sul: Editora da UNISC, 1994, p. 129-140. [BSCSH/UFRGS, CENTRAL/PUCRS, UNISC, UCS].

OLIVEN, Ruben. A invisibilidade social e simbólica do negro no Rio Grande do Sul. In: LEITE, Ilka Boaventura. (Org.). Negros no Sul do Brasil: invisibilidade e territorialidade. Florianópolis: Letras Contemporâneas, 1996. pp. 13-32.

PESAVENTO, Sandra Jatahy. A construção de uma Porto Alegre imaginária - uma cidade entre a memória e a história. In: GRIJÓ, Luiz Alberto et al (Org.). Capítulos de História do Rio Grande do Sul. Porto Alegre: Ufrgs, 2004. Cap. 7. p. 179-208.

Os pobres da cidade: vida e trabalho (1880-1920). Porto Alegre: Ed. da Universidade/UFRGS, 1994.

SANTOS, Irene (org.). Negro em Preto e Branco: história fotográfica da população negra de Porto Alegre. Porto Alegre: Do Autor, 2005. 